\title{
Automatic Identification System in Maritime Traffic and Error Analysis
}

\section{Rino Bošnjak, Ljupko Šimunovića ${ }^{2}$ Zvonko Kavran ${ }^{a}$}

Automatic Identification System (AIS) is used for security of ships and ports, their identification and protection of marine environment.

Correct installation of AIS device and integration with navigation equipment is of great importance for the correct functioning of the system. To increase system accuracy correct input of data to the system is significant. Correct data interpretation depends on seafarer's ability to recognize errors. In order for the seafarer to get acquainted with the system as well as its advantages and disadvantages high-quality seafarers' training in the use of AIS is of utmost importance. AIS is not a navigation aid, nevertheless it can be used as a device to facilitate navigation.

In this paper the authors are analysing AIS errors and proposing measures for improvement of its functioning.

\section{KEY WORDS}

$\sim$ AIS

$\sim$ Errors

$\sim$ Security

$\sim$ Protection

University of Split, Faculty of Maritime Studies, Zrinsko-Frankopanska 38, 21000 Split, Croatia

e-mail: rbosnjak@pfst.hr

a. University of Zagreb, Faculty of Traffic Sciences, Vukelićeva 4, 10000 Zagreb

e-mail: ljupko.simunovic@fpz.hr, zvonko.kavran@fpz.hr

\section{INTRODUCTION}

Automatic Identification System (AIS) contributes to the security of ships and ports, their identification and protection of marine environment. The system recognizes ships and coastal stations and provides data on their characteristics. On board ships it is integrated with other navigation aids:

- Global Positioning System-GPS;

- $\quad$ Electronic Chart Display Information System-ECDIS;

- Voyage Data Recorder-VDR;

- $\quad$ RAdio Detection And Ranging-RADAR;

- $\quad$ ARPA (Automatic Radar Plotting Aid).

According to 2000 Safety of Life at Sea-SOLAS Convention, Chapter V, Rule 19 mandatory navigation equipment dependant on the type of vessel is defined. International Maritime Organization- IMO has adopted new requirements which lay down AIS system as mandatory. IMO regulation refers to all vessels of $300 \mathrm{GT}$ or more in international traffic, cargo vessels of $500 \mathrm{GT}$ or more not operating on international voyages and to all passenger vessels regardless of their size. This decision has been implemented since December 31, 2004 and refers to:

- $\quad$ Passenger vessels built (completed) not later than July 1, 2003;

- Tankers which had their first security check or survey after July 1, 2003;

- $\quad$ All ships, except passenger ships and tankers, of more than 500 GT (eng. Gross Tonnage - unit denoting the overall volume of ship's internal spaces ) built not later than July 1 , 2004. 


\section{AIS DATA ANALYSIS}

For successful functioning AIS requires successive updating and repeated transmission of messages in short time intervals. Usefulness of AIS data is reduced within time function ( $t$ ):

$$
\begin{aligned}
& f(K) \rightarrow \max \Leftrightarrow t \rightarrow \min \\
& K \quad \text { data usefulness, } \\
& t \quad \text { time lapse. }
\end{aligned}
$$

In order to allow time-synchronised updating, a common self-organisational communication scheme of time distribution has been introduced.

\section{AIS USAGE WITH REGARD TO TYPE OF INFORMATION}

Use of two types of AIS devices, type A and type B has been laid down as mandatory (Figure 1).

Type A is mandatory for vessels of 300 GT or more operating on international voyages, cargo vessels of $500 \mathrm{GT}$ or more not operating

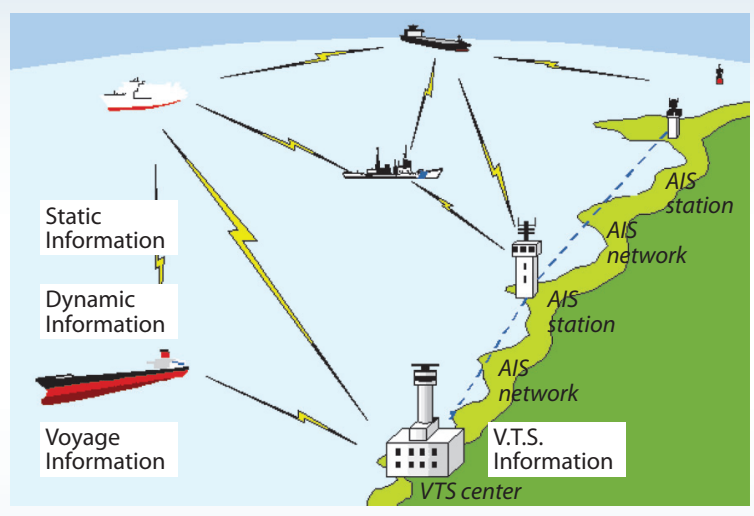

Figure 1. Automatic identification system data. Source: http://www6.kaiho.mlit.go.jp/kanmon/eng/mg_2.htm

on international voyages and for passenger vessels (carrying more than 12 passengers) regardless of their size. It is estimated that about 40,000 vessels (AIS, 2012) nowadays use type $A$.

Table 1. Automatic identification system.

Antenna position

MMSI number (Maritime Mobile Satellite Identity-MMSI)

Static Data

Ship's call sign and name

IMO number

Ship's length and beam

Ship's type

Ship's position with indication of accuracy (automatic updating using DGPS (eng. Differential Global Positioning System) sensor connected to AIS)

Time in UT (eng. Universal Time - Central European Time)

Dynamic Data

Speed over ground

Course over ground

Navigational status ( self-propelled, anchored, unable to manoeuvre, of restricted ability to manoeuvre, moored, restricted by draught, aground, engaged in fishing or sailing boat)

Angular velocity

Ship's draught

Voyage Dangerous cargo

Related Data Port of destination and ETA

Passage plan

VTS data

Short content information related to various safety warnings and information on areas with warnings about navigational and other dangers. The data should be addressed to AIS receiver for all ships and coastal stations within range. 


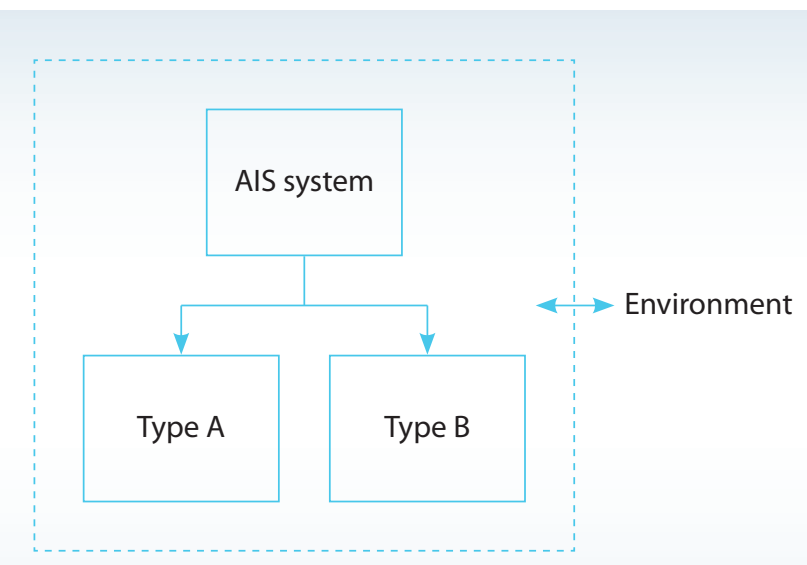

Figure 2. Distribution of Automatic identification system.

Type B allows for a new generation of AIS devices which are available at lower prices, of limited range and characteristics. The difference between AIS devices of classes A and B is shown in Table 2 .
In case the output data from the elements of sets $O_{1}-P_{1}$ and $\mathrm{O}_{2}-P_{2}$ are observed via time function the following is valid:

$f(t 1) \quad-2-10$ seconds (time interval for element $o$, for device class $A$ ),

$f\left(t_{2}\right) \quad-6$ minutes (time interval for element $o_{2}$ for device class $A$ ),

$f\left(t_{3}\right) \quad-30$ seconds (time interval for element $o_{3}$ for device class B).

The following algorithm is proposed to represent time functions for each element of the above mentioned sets (Figure 3).

\section{AIS ERROR ANALYSIS}

The system and errors to which AIS is subjected can be represented by the following model:

For the model shown in Figure 4 designation (T) for technical errors and designation $(\mathrm{H})$ for human errors are proposed.

In the operation of AIS system errors caused by human factor occur. Various methods of investigating AIS device errors in which human factor was principal have been conducted (Mohktari, 2007). The errors can be classified as:

- $\mathrm{MMSI}_{\text {, }}$

Table 2. Output data of Automatic identification system devices class A and B. Source: http://www.navcen.uscg. gov/?pageName=types AIS

\section{DEVICE CLASS A}

\begin{tabular}{|c|c|c|c|c|c|c|c|}
\hline \multicolumn{4}{|c|}{ DEVICE CLASS A } & \multicolumn{4}{|c|}{ DEVICE CLASS B } \\
\hline Transmission & $\begin{array}{c}\text { Proposal for } \\
\text { designation } \\
O_{1}\end{array}$ & Reception & $\begin{array}{c}\text { Proposal for } \\
\text { designation } \\
P_{1}\end{array}$ & Transmission & $\begin{array}{c}\text { Proposal for } \\
\text { designation } \\
\mathrm{O}_{2}\end{array}$ & Reception & $\begin{array}{c}\text { Proposal for } \\
\text { designation } \\
P_{2}\end{array}$ \\
\hline General data & $a o_{1}$ & General data & $a p_{1}$ & General data & $a o_{1}$ & General data & $a p_{1}$ \\
\hline Static data & $a O_{2}$ & Static data & $a p_{2}$ & $\begin{array}{l}\text { Does not transmit } \\
\text { IMO number and } \\
\text { call sign }\end{array}$ & $b_{2}$ & Static data & $b p_{2}$ \\
\hline Dynamic data & $a O_{3}$ & $\begin{array}{l}\text { Dynamic } \\
\text { data }\end{array}$ & $a p_{3}$ & $\begin{array}{l}\text { Does not transmit } \\
\text { dynamic data } \\
\text { (ETA - Estimated } \\
\text { Time of Arrival, } \\
\text { destination, } \\
\text { navigational } \\
\text { status) }\end{array}$ & $b_{3}$ & $\begin{array}{l}\text { Dynamic } \\
\text { data }\end{array}$ & $b p_{3}$ \\
\hline Text messages & $a O_{4}$ & $\begin{array}{c}\text { Text } \\
\text { messages }\end{array}$ & $a p_{4}$ & $\begin{array}{l}\text { Does not transmit } \\
\text { text messages }\end{array}$ & $b_{4}$ & $\begin{array}{c}\text { Text } \\
\text { messages }\end{array}$ & $b p_{4}$ \\
\hline Binary messages & $a O_{5}$ & $\begin{array}{c}\text { Binary } \\
\text { messages }\end{array}$ & $a p_{5}$ & $\begin{array}{l}\text { Does not transmit } \\
\text { binary messages }\end{array}$ & $b_{5}$ & $\begin{array}{c}\text { Binary } \\
\text { messages }\end{array}$ & $b p_{5}$ \\
\hline Ship's rate of turn & $a o_{6}$ & $\begin{array}{l}\text { Ship's rate of } \\
\text { turn }\end{array}$ & $a p_{6}$ & $\begin{array}{l}\text { Does not transmit } \\
\text { ship's rate of turn }\end{array}$ & $b_{6}$ & $\begin{array}{l}\text { Ship's rate of } \\
\text { turn }\end{array}$ & $b p_{6}$ \\
\hline Ship's draught & $\mathrm{aO}_{7}$ & $\begin{array}{l}\text { Ship's } \\
\text { draught }\end{array}$ & $a p_{7}$ & $\begin{array}{l}\text { Does not transmit } \\
\text { ship's draught }\end{array}$ & $b_{7}$ & $\begin{array}{l}\text { Ship's } \\
\text { draught }\end{array}$ & $b p_{7}$ \\
\hline
\end{tabular}




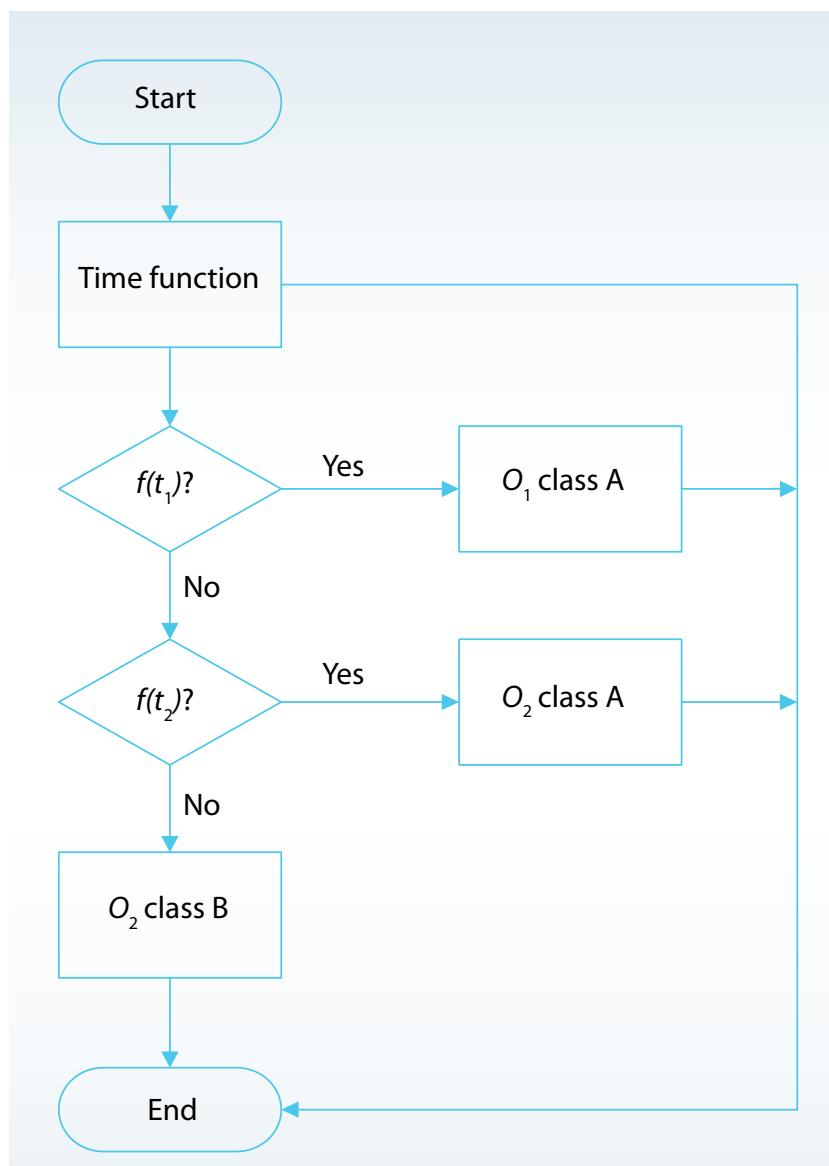

Figure 3. Algorithm of representation of time functions for particular elements from sets $\mathrm{O}_{1}-\mathrm{P}_{1}$ and $\mathrm{O}_{2}-\mathrm{P}_{2}$.

- Ship's type,

- Name and call sign,

- Ship's navigational status,

- Ship's length and breadth,

- Ship's draught,

- Destination and time of arrival to destination,

- $\quad$ Other problems related to AIS device.

More different vessels transmit the same MMSI number (eng. Maritime Mobile Service Identity - identification number of a maritime mobile station). During research it has become apparent that the same MMSI number 1193046 is transmitted by more than one different vessels. It is possible that this number was adapted to a specific model of AIS device and the reason is wrongly adapted equipment at the time or specific errors of equipment. It was recorded that 26 vessels were transmitting the above mentioned MMSI number and wrong ship's information). The responsibility of the navigating officer of watch on the bridge is to check the data of the above mentioned number in the AIS

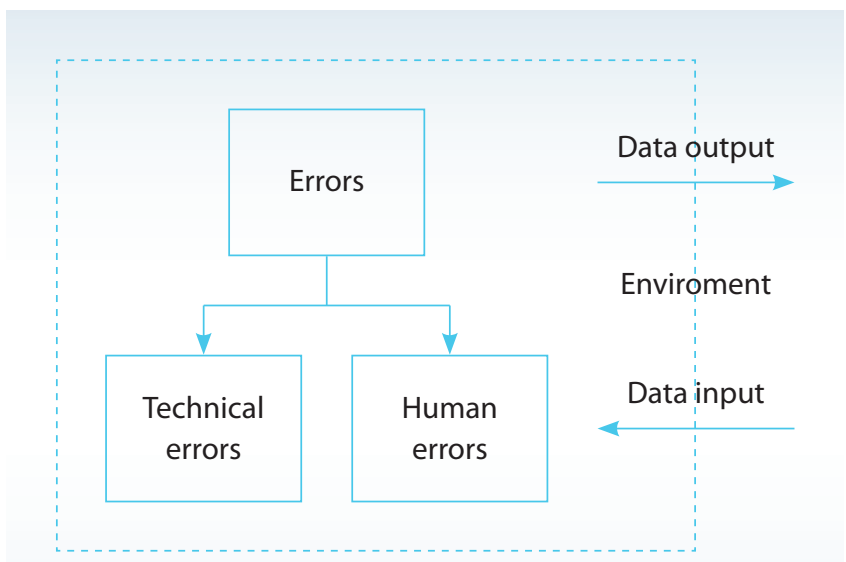

Figure 4. General model of Automatic identification system errors.

device before each voyage.

Ships with common features are identified in AIS receiver as same. Such an error occurs due to an insufficient number of categories within AIS device to cover all types of ships sailing the seas worldwide. For example, the more common types of ships such as container ships, bulk carriers or car carriers are shown on AIS receiver as cargo ships. The same is valid for tankers as there is no further classification into subtypes (e.g. product tankers, liquefied gas carriers or chemical carriers) but they are generalized as tankers.

The investigations show that there were no errors with ship's name or ship's call sign on AIS device. Instead of the name or call sign there is a blank space. Without the name or call sign there were altogether $0.5 \%$ of AIS messages recorded during investigation. Another problem is the use of abbreviated ship's name due to a lack of or an insufficient number of characters available on the device itself. The errors mentioned above occur due to installation or design which does not allow for the ship's name to contain more than 20 characters (Khisty and Lall, 2003).

In the investigations related to AIS receiver $30 \%$ of ships were represented with wrong navigational status. $4 \%$ of ships were represented with the status of a sailing vessel instead of the status of a power-driven vessel. Furthermore, it was shown that a ship was proceeding at the speed of 10 knots while on AIS device the ship was represented with the status 'berthed" (the cause of the last example often leads to overload of the master or officer during setting sail when the device has to be updated).

On AIS receiver $47 \%$ of ships show wrong length (d) (Graph 1) whereas $8 \%$ show wrong breadth (b) within AIS information (Graph 2) (Ewing, 2010).

Incorrect draught information occurs in $17 \%$ of input data to AIS. It was also observed that in $14 \%$ of cases AIS input for draught is higher than the ship's length. In the remaining $69.5 \%$ 
of cases it was difficult to determine if the data were correct (Vidan et al., 2010).

Destination and arrival to destination - errors to destination and Estimated Time of Arrival - ETA make 49\% of errors. The most common errors that occur are:

- Number instead of port of destination,

- Name of the country instead of name of the port,

- Unknown abbreviation,

- Information "unavailable",

- Information "unidentified",

- Null or blank space.

This error is considered important in a heavy traffic area. It is very useful to know the correct information about the destination of the vessel shown on AIS receiver that is to be avoided.

Other problems related to AIS device - AIS device cannot be used for:

- Collision avoidance at sea,

- Separation scheme zones,

- $\quad$ Search and rescue.

In the analysis regarding the types of technical errors ( $T$ ) two possible working conditions can be observed, i.e.:

- Condition $D_{1}$ (technical errors $\left.t_{4}-t_{7}\right)$,

- Condition $D_{2}$ (technical errors $t_{1}-t_{3}$ ).

When the device is in working condition $\left(D_{1}\right)$ - it continues functioning regardless of the error which occurred. In case AIS device is in working condition $\left(D_{2}\right)$, it does not continue to function correctly due to the effect of the error. Since with AIS device there are two possible conditions $D_{1}$ and $D_{2}$ it is necessary to classify technical errors $(T)$ and their effects on the functioning

- Ship's length

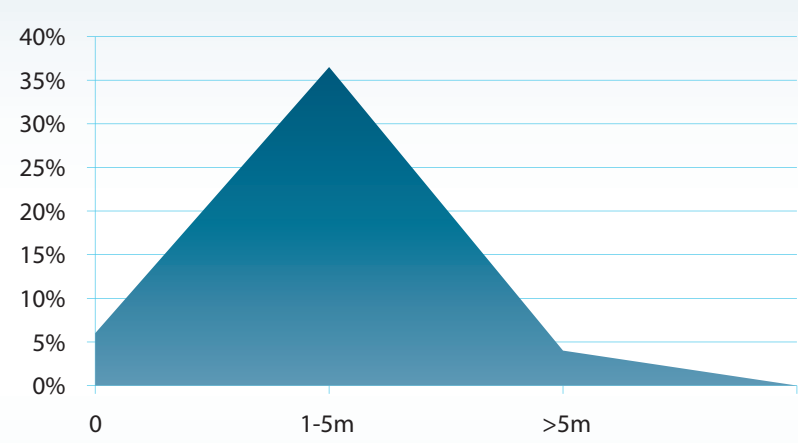

Figure 5. Ships showing wrong length. Source: Abbas Harati-Mokhtari (Liverpool John Moores University, UK) available at: http://94.211.137.110/middenlimburg/downloads/documenten/ pdf/AIS_Human_Factors.pdf, 21.12.2011. of AIS device according to device condition $\left(D_{1}\right.$ or $\left.D_{2}\right)$. Description of technical errors of ( $T$ ) AIS device:

$t_{1}$ no transmission / AIS device stops transmitting information;

$t_{2}$ no reception on working frequencies/ AIS device stops transmitting on all channels $(\mathrm{n})$;

$t_{3}$ general error / AIS device stops transmitting on all channels ( $\mathrm{n}$ );

$t_{4}$ no information on position / AIS device continues functioning using internal GPS device;

$t_{5} \quad$ no speed over ground / AIS device continues functioning but does not show information on speed;

$t_{6} \quad$ no course over ground / AIS device continues functioning but does not show information on course;

$t_{7}$ no information on the rate of turn- ROT (eng. Rate of Turn device showing intensity of alteration of course and side to which the vessel will turn).

The requirement for AIS is correct functioning. In case any of the errors occurs ( $\mathrm{H}$ or $\mathrm{T}$ ) the device is faulty. The analysis of possible errors is shown by algorithms of conditions $D_{1}$ and $D_{2}$ (Figures 4 and 7).

\section{PROPOSAL OF AIS IMPROVEMENT}

The role of AIS in collision avoidance at sea is significant. AIS device shows ready-made information which are relevant for collision avoidance. As a difference from ARPA (eng. Automatic RAdar Plotting Aid) which calculates data, AIS receives ready-made information from other ships' gyro compasses. The information is shown on ECDIS or on radar display. The correct installation of AIS device and its integration with navigational equipment, accuracy of data hand-fed into the system and the ability of seafarers to correctly understand information received by AIS device are

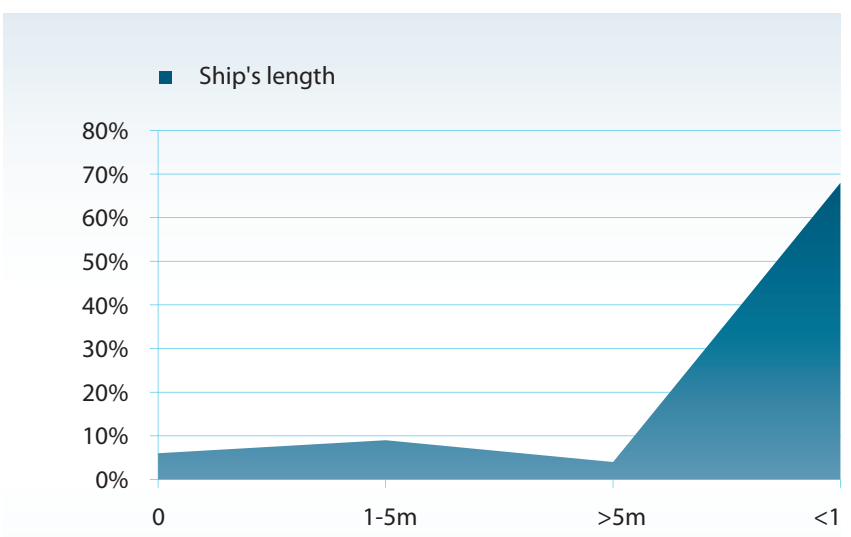

Figure 6. Ships showing wrong breadth. Source: Abbas Harati-Mokhtari (Liverpool John Moores University, UK available at: http://94.211.137.110/middenlimburg/downloads/documenten/ pdf/AIS_Human_Factors.pdf, Dec. 21, .2011. 


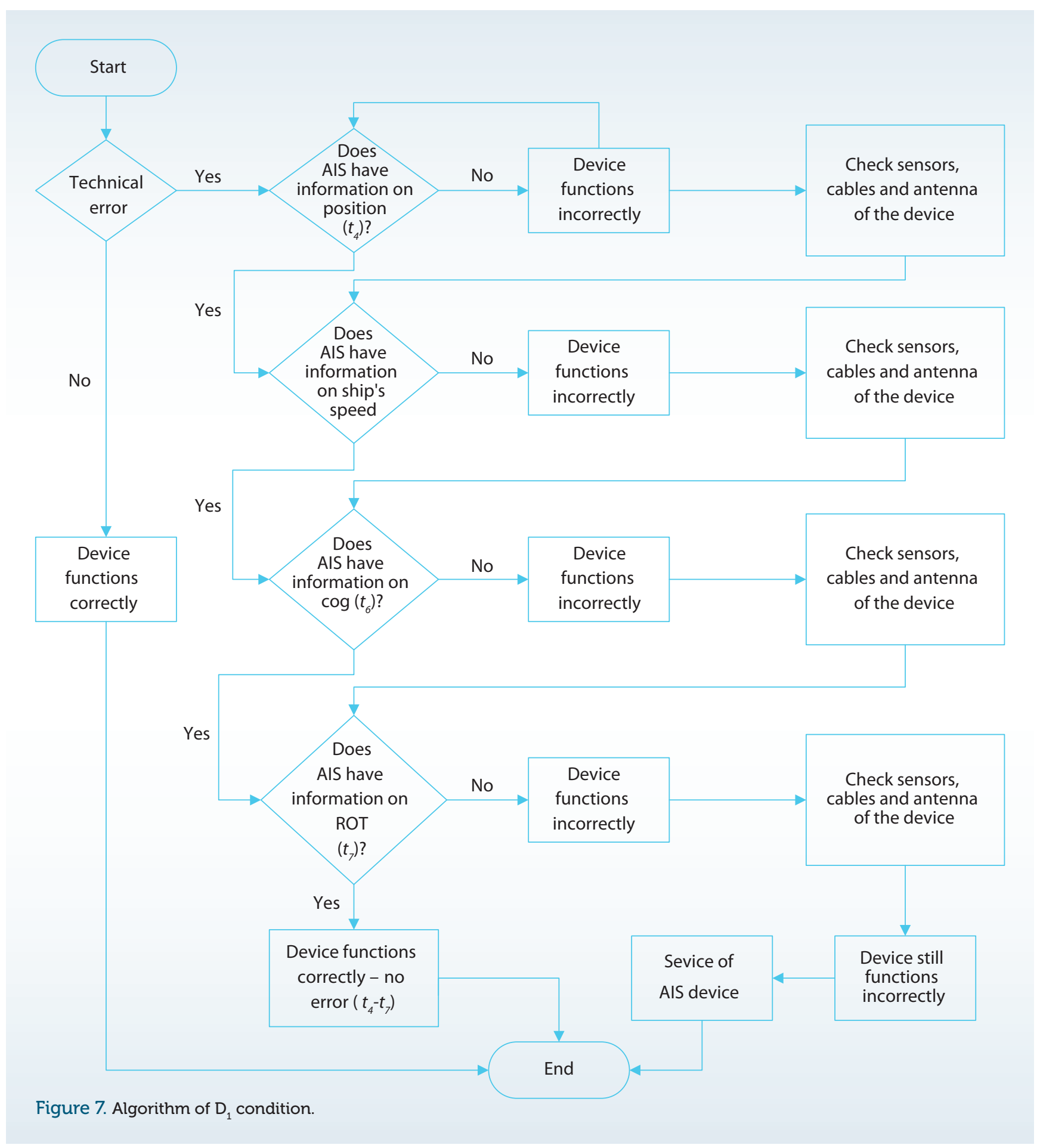

important to avoid problems related to the functioning of the device. The installation of AIS device and seafarer training (Figure 8 ) in the use of this equipment are very important which was not really considered a priority in the beginnings.
AIS information received from VTS system are important in the investigation of maritime accidents. The information consist of accurate time, GPS position, course over ground, speed over ground, ship's rate of turn and all of them are included in maritime 


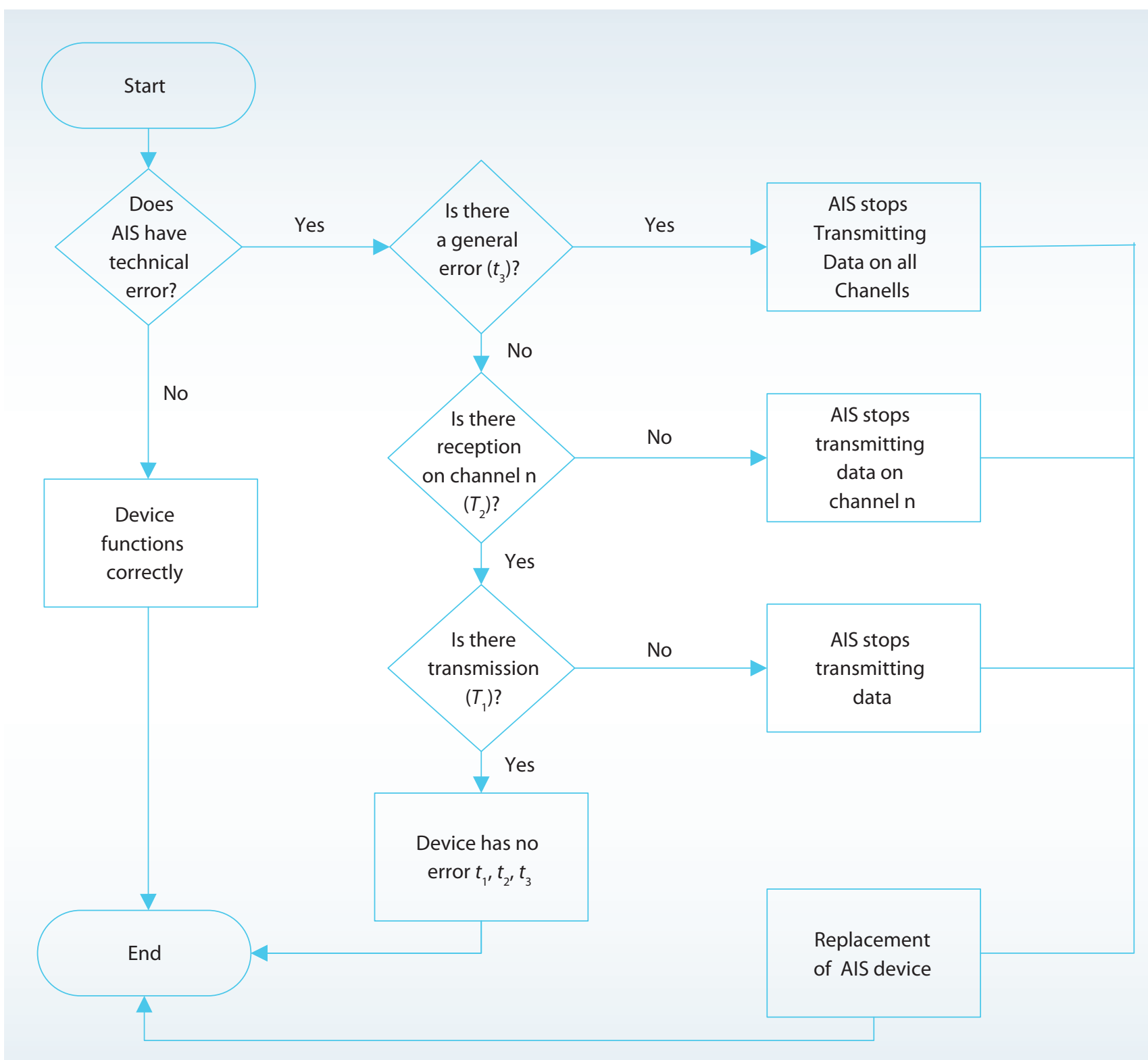

Figure 8. Algorithm of $\mathrm{D}_{2}$ condition.

accident investigation as they are of great help in solving such accidents.

With the introduction of new measures, the following factors are proposed:

1. A1 denotes correct use of AIS device in port. In practice it has been observed that after manoeuvring and berthing the vessel the master or officer of watch do not change the ship's status on AIS device. Therefore, it shows the information for the vessel as being underway instead of "berthed".

2. A2 denotes the correct use of the device while underway. It refers to updating of ship's draught, port of destination, time of arrival to port of destination, type of cargo that the ship is carrying, etc.

3. A3 refers to functioning of AIS device on longer distances. AIS device functioned on VHF frequencies on shorter distances. Nowadays, the satellite AIS signal is available in different parts of the world and this availability is applied via Satellite Based System AIS-S. The device does not require 
any action from the vessel as a difference from Long Range Identification Tracking- LRIT (Long Range Identification and Tracking, 2012).

4. A4 refers to the correct use of the device by the officer of watch. It refers to his acquaintance with the device and a possible need for the familiarization with the device before starting to use it.

5. A5 refers to testing the device with coastal stations. It is necessary to test the device with a coastal station to confirm the correct reception or transmission.

6. A6 refers to testing the device so as to confirm its correct functioning.

\section{CONCLUSION}

It has been found out that AIS provides more accurate information than ARPA device; however AIS is not a device reliable enough for avoiding collisions at sea. AIS is not installed on all ships, and the quality of data input by the navigator is questionable. Besides all mentioned above AIS exhibits technical imperfections that should be removed to achieve its full functionality in navigation.

The control of the entire system in determined time intervals, checking of information accuracy and removal of defects are proposed Besides technical errors human errors also occur. Regarding the frequency of human errors additional attention and training of operators themselves are considered necessary in order to follow the development of AIS and its upgrade.

Measures are proposed that are necessary to minimize the error caused mainly by human operator with the introduction of time intervals required for familiarization with the device itself before starting to use it.

The entire system is still in an initial phase of its development so that its still wider and probably more enhanced application can be expected in the forthcoming times.

\section{REFERENCES}

Abbas Harati, Mohktari AIS, (2007), A human factors approach- Abbas Harati - Mohktari available at: http://www.mendeley.com/research/automaticidentification-system-ais-data-reliability-human-error-implications/\#page-1 [accesed 16 march 2012].

AIS, (2012), available at: http://wikipedia.org/wiki/AIS, [accessed 17 February 2012].

Badurina, E., (2002), Pomorski Zbornik 40, pp. 79-94

Baljak, K., Vidan, P., (2006), Global ship reporting system and automatic identification system, GIS Applications and Development / Zagreb; Katowice: Hrvatski Informatički Zbor- GIS Forum; University of Silesia, pp.77-83

Ewing, K.C. \& Fairclough, S.H., (2010), The impact of working memory load on psychophysiological measures of mental effort and motivational disposition.

Long Range Identification and Tracking, available at: wikipedia.org/wiki/Long_

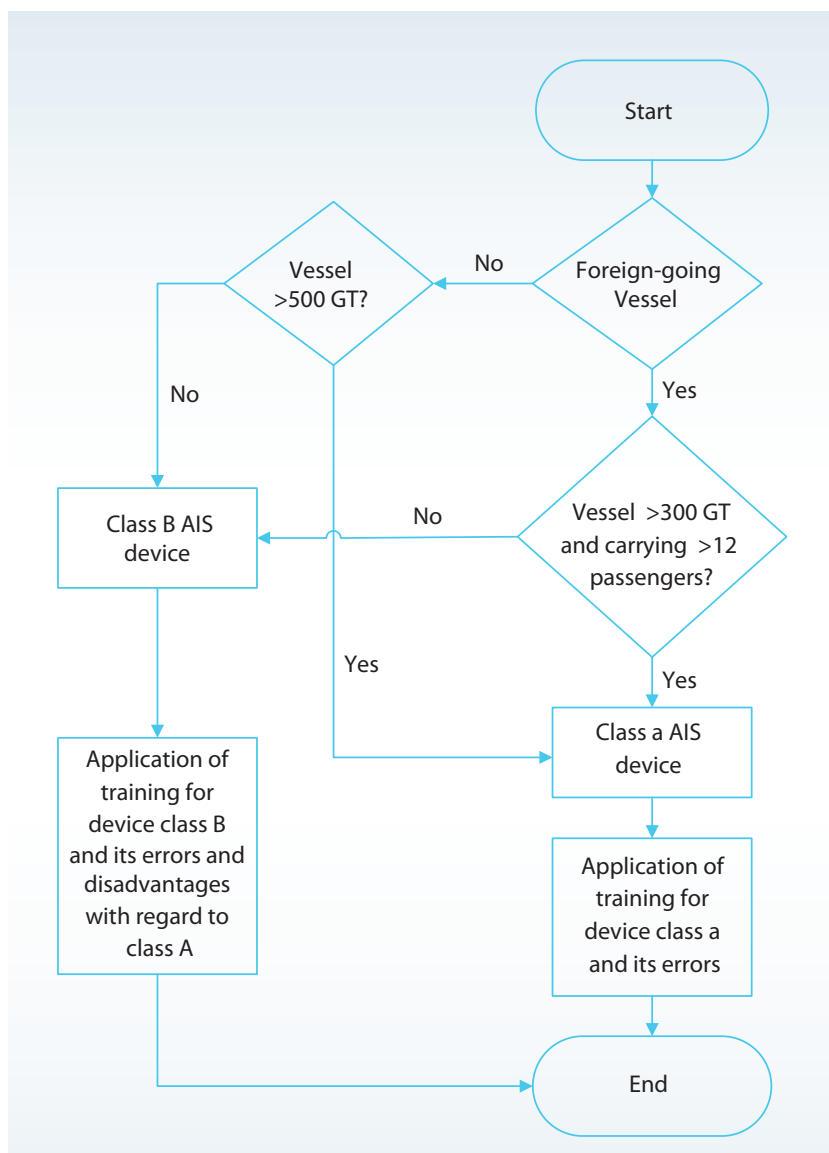

Figure 9. Algorithm of improvement of seafarers' training for AIS equipment.

Range_Identification_and_Tracking, [accesed 28 February 2012].

IMO, (2012), available at: www.imo.org/ourwork/safety/navig./pages/ais, [accesed 21 February 2012].

IMO, (2012), available at: www.imo.org/SharePoint/mainframe.asp, [accesed 28 February 2012].

IALA (2012), available at: http:// site.ialathree.org/pages/AIS/aisfaq.pdf [accesed 12 march 2012].

Kanmon -Kaikyo Traffic Advisory Service (VTS) Center (2012), available at: http:// www6.kaiho.mlit.go.jp/kanmon/eng/mg_2.htm, [accesed 16 march 2012].

Khisty, C. J., Lall, B.K., (2003), Transportation Engineering: An Introduction, Third edition, Prentice Hall, New Jersey: Prentice Hall.

Mohktari, A. H., (2007), Automatic Identification System "A human factor approach" Liverpool John Moores University, UK

Split Port Authority, Split-Croatia (2012), available at: www.portsplit.com, [accesed 16 march 2012].

Vidan, P., Kasum, J., Zujić, M., (2010), Meteorlogical Navigation and ECDIS, Promet, 22(5), pp. 373-378.

Vidan, P., Kasum, J., Jolić, N., (2010), A proposal for the models and measures of search and rescue on inland waterways, Promet, 25(2), pp. 178-185. 